\title{
Overexpression of S-adenosylmethionine decarboxylase impacts polyamine homeostasis during development of Dictyostelium discoideum
}

\author{
PRIYANKA SHARMA, RISHIKESH KUMAR and SHWETA SARAN* \\ School of Life Sciences, Jawaharlal Nehru University, New Delhi, India
}

\begin{abstract}
The polyamines putrescine, spermidine and spermine are essential polycations involved in the regulation of cellular proliferation. They exert dynamic effects on nucleic acids and macromolecular synthesis in vitro but their specific functions in vivo are poorly understood. Here, we have modulated the spermidine levels either by overexpressing the $S$-adenosylmethionine decarboxylase (samdc) gene or treating the cells with methylglyoxal-bis (guanylhydrazone) (MGBG), an inhibitor of SAMDC. In Dictyostelium, overexpression of SAMDC slowed cell proliferation, delayed development and arrested cells in the S-phase of the cell cycle. Treatment with MGBG reduced cell proliferation and stimulated development, but in samdc ${ }^{O E}$ cells, it increased cell proliferation suggesting critical levels of spermidine to be important. In samdc ${ }^{O E}$ cells, spermidine levels remained high throughout development but only small changes in the spermine levels were observed. Initial putrescine levels did increase but reverted to wild-type levels after the mound stage. As tight regulation of polyamine homeostasis is required, we identified genes that could be involved in its maintenance. In conclusion, we characterised $\operatorname{samdc}^{O E}$ cells and observed the maintenance of polyamine homeostasis during the development of Dictyostelium cells.
\end{abstract}

KEY WORDS: Dictyostelium, SAMDC, polyamine, transporter, homeostasis

The naturally abundant polyamines (PAs), putrescine (put, diamine), spermidine (spd, triamine) and spermine (spm, tetramine) are involved in various cellular processes like modulation of chromatin structure, gene transcription and translation, DNA stabilization, signal transduction, cell growth and proliferation (Handa et al., 2018). Increased PA levels are coupled with increased cell proliferation, decreased apoptosis and increased expression of genes associated with tumor invasion and metastasis, thus making their metabolism a target for cancer treatment and prevention (Ye et al., 2016). The free cellular PA pools are maintained within a very narrow range and is regulated in a precise manner, which is achieved at four levels: de novo synthesis, inter-conversion, terminal degradation and transport (Wallace, 1996).

Dictyostelium discoideum is a good model system to analyse the functions related to growth and differentiation. It lives as a unicellular amoeba when feeding on bacteria but upon starvation they aggregate at common collecting points to undergo development into multicellular structures. Muticellularity arises due to the coming together of the spatially segregated cell-types, which undergo various morphogenetic movements to finally culminate into a fruiting body consisting of viable spores and dead stalk cells (Tarnita et al., 2015).

Earlier, we showed the involvement of put in growth control and spd in development of Dictyostelium (Saran, 1998; Kumar et al., 2014). Here, we modulated the levels of spd, (which in turn modulates other PA levels) by constitutively expressing the samdc gene $\left(\right.$ samd $^{O E}$ ) and/or by treatment with exogenous methylglyoxal-bis (guanylhydrazone) (MGBG), an inhibitor of SAMDC (Regenass et al., 1992). During PA biosynthesis, S-adenosyl-L-methionine decarboxylase (SAMDC, EC 4.1.1.50) converts the methyl donor and ethylene precursor S-adenosyl-L-methionine (SAM), to decarboxylated S-adenosyl-L-methionine. Decarboxylated SAM serves as an aminopropyl donor in the synthesis of higher PAs, spd and spm from the put (Moschou et al., 2008) (Supplementary Fig S1).

Abbreviations used in this paper: MGBG, methylglyoxal-bis (guanylhydrazone); ODC, ornithine decarboxylase; PA, polyamine; put, putrescine; SAMDC, S-adenosylmethionine decarboxylase; spd, spermidine; spm, spermine.

\footnotetext{
*Address correspondence to: Shweta Saran. School of Life Sciences, Jawaharlal Nehru University, New Delhi-110067, India. E-mail: ssaran@mail.jnu.ac.in; shweta_saran@hotmail.com - iD https://orcid.org/0000-0002-0238-498X
}

Supplementary Material (8 figures and one table) for this paper is available at: https://doi.org/10.1387/ijdb.180167ss 
We show samdc ${ }^{O E}$ cells are slow growers, arrest in S-phase and has a bias towards stalk pathway. Also, the absolute spd level was high during terminal differentiation, no significant change in spm levels but initial put level was increased. This prompted us to observe the developmental changes in catabolic, anabolic and transporters involved in PA homeostasis.

\section{Results}

\section{Overexpression of samdc (samdc ${ }^{O E}$ )}

The phylogenetic tree shows DdSAMDC to be closer to Heterostelium album (Heterostelium gen. nov. Acytosteliaceae) and shares $45 \%$ similarity with humans (Supplementary Fig. S2A, B). We earlier expressed the samdc gene (DDB_G0275567) as a fusion protein with the eYFP reporter at the C-terminal under actin15 promoter (Supplementary Fig. S2C; Kumar et al., 2018). The samdc transcript levels increased till the slug stage, after which it decreased till fruiting body formation. The fusion protein showed largely cytosolic localization (Supplementary Fig. S3A, B).

\section{Effect of methylglyoxal-bis (guanylhydrazone) (MGBG)}

The intracellular spd levels were modulated both at the genetic level by creating samd $C^{O E}$ and biochemically by treating with MGBG. Interestingly, the level remained higher than that observed in Ax2 cells upon treatment with MGBG, in case of samdc ${ }^{O E}$ cells
(Supplementary Fig. S2D)

Fig. 1A shows cell proliferation in Ax2 and samdc ${ }^{O E}$ cells both in the presence and absence of MGBG. Both control and MGBG treated Ax2 cells showed maximum cell density of $13.5 \times 10^{6} \pm$ 0.81 and $7.1 \times 10^{6} \pm 0.26$ cells $/ \mathrm{ml}$, respectively at 72 after which it declined. On the other hand, samd ${ }^{O E}$ cells showed a longer lag period of $24 \mathrm{~h}$ and reached maximum cell density of $13.93 \times 10^{6} \pm$ $0.7 \mathrm{cells} / \mathrm{ml}$ by $\mathrm{t} 96$. Interestingly the decline was not pronouced till t120. Upon treatment with MGBG we observed a longer lag period with maximum cell density of $12.63 \times 10^{6} \pm 0.17$ cells $/ \mathrm{ml}$ at $\mathrm{t} 72$ and a decline thereafter. The size of $A \times 2$ and samdc ${ }^{O E}+M G B G$ cells were more or less similar, while MGBG treated Ax2 cells and the samd ${ }^{O E}$ cells had increased (Fig. 1B).

Cell-viability during cell proliferation was examined through cell regrowth and MTT assay (Supplementary Fig. S3 C,D). Cell regrowth was analysed in aging population where t0 indicates the time from midpoint of stationary culture (Jain et al., 2016). A sharp decrease upon MGBG treatment of Ax2 cells as compared to untreated was observed. Nearly $50 \pm 0.38 \%$ cell death after $72 \mathrm{~h}$ in both the cases was observed. Cell survival was better in samd $^{O E}$ cells but reduced to nearly $50 \pm 2.62 \%$ by $72 \mathrm{~h}$. Upon MGBG treatment the survival was comparable to Ax2 cells alone. Both Ax2 and samdc ${ }^{O E}$ cells showed a decline after $96 \mathrm{~h}$ but upon MGBG treatment, it reduced significantly after $24 \mathrm{~h}$ and reached nearly $50 \pm 1.63 \%$ by $120 \mathrm{~h}$ in Ax2 cells but the decline was not to

A

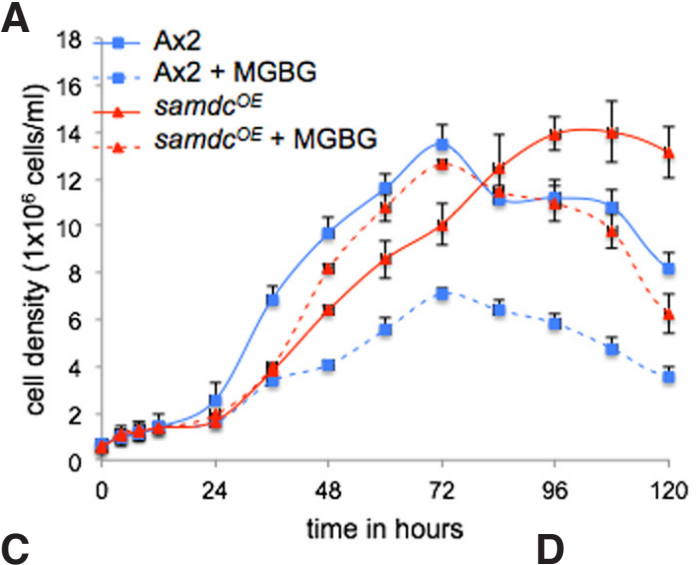

B

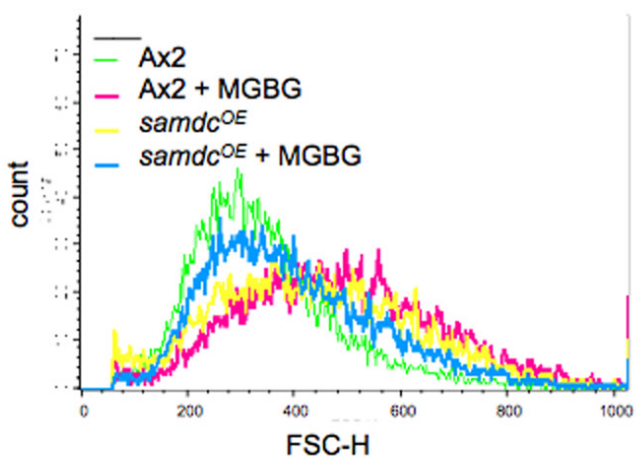

$\mathbf{E}$
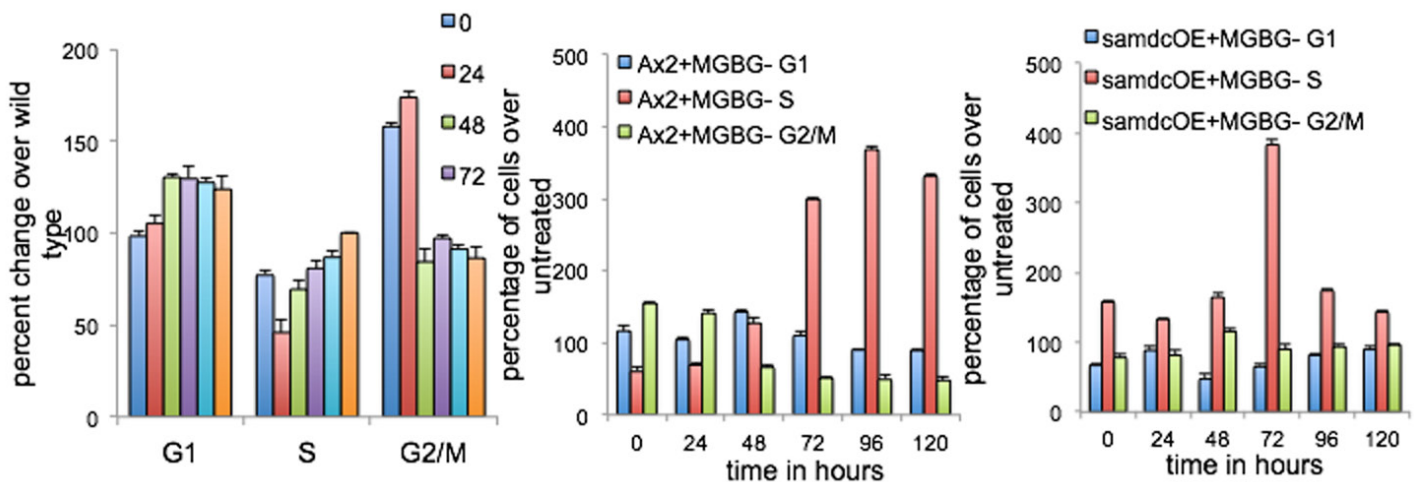

Fig. 1. Effect of methylglyoxal-bis (guanylhydrazone) (MGBG) on cell proliferation, cell size and cell cycle. (A) Cell proliferation studies with Ax2, samdc ${ }^{\mathrm{OE}}$ in the presence and absence of MGBG. The samdc ${ }^{\mathrm{OE}}$ cells showed slow cell proliferation. (B) Cell-size analysis of wild-type and samdc ${ }^{\mathrm{OE}}$ cells in the presence and absence of MGBG (1 mM) at different time-points (0,24, 48, 72, 96 and $120 \mathrm{~h})$. (C) Bar diagram represents relative percent over the wild-type in samdc ${ }^{\mathrm{OE}}$ cells at different time points. Data represents relative percentage of cells after treatment with MGBG and normalization with untreated of the same time-point for (D) $A \times 2$ and (E) samdc ${ }^{\mathrm{EE}}$. $(n=3)$. 
the same extent for samdc ${ }^{O E}$ cells.

The differences in cell proliferation prompted us to analyze cell cycle progression. Fig. 1C shows the percent change over Ax2 cells at the given time-points for samdc ${ }^{O E}$ cells. An increase in S-phase over time and a corresponding decrease in G2/M-phase was observed. Similar results were obtained with MGBG treatment in Ax2 cells (Fig. 1D). MGBG treatment showed an increase in S-phase till $72 \mathrm{~h}$ and a decline thereafter over untreated samdc ${ }^{O E}$ cells (Fig. 1E). Insignificant changes in the G2/M-phase and a small decrease in G1-phase was observed.

Further, cells were plated at equal densities $\left(5 \times 10^{7}\right.$ cells $\left./ \mathrm{ml}\right)$ and allowed to complete development after synchronization (Fig. 2A). Ax2 cells completed their development by forming aggregation territories by $12 \mathrm{~h}$, slugs at $16 \mathrm{~h}$ and culminant by $24 \mathrm{~h}$. All three, $\mathrm{Ax} 2+\mathrm{MGBG}$, samd $\mathrm{c}^{O E}$ and samdc ${ }^{O E}+\mathrm{MGBG}$ showed asynchrony and developed small-sized territories as compared to untreated Ax2 cells. All samdc ${ }^{O E}$ aggregates did not culminate into fruiting bodies and showed aborted intermediates. Fig. 2B shows enlarged images of the fruiting bodies formed. MGBG treated Ax2 cells formed fruiting body with small sorus and stouter stalk and basaldisc. The samdc ${ }^{O E}$ cells formed very long stalks with small sorus but upon MGBG treatment, stalks became stouter but shorter than the untreated cells. Further, upon MGBG treatment, spore-viability of Ax2 cells decreased (35.33 $\pm 4.04 \%$ ) while no change (89.6 $\pm 2.51 \%$ ) was observed with samdc ${ }^{O E}$ cells (Supplementary Fig. S4A). Upon MGBG treatment, the number of aggregates formed by Ax2 cells increased (nearly $40 \%$ ) and a very small decline was observed with samd $C^{O E}$ cells (Supplementary Fig. S4B). The size of the aggregates formed after MGBG treatment, decreased (nearly 5 folds) in the Ax2 cells but increased in samdc ${ }^{O E}$ cells (Supplementary Fig. S4C). The stalk length was higher (nearly two-folds) in case of samdc ${ }^{O E}$ cells but decreased upon MGBG treatment. A decrease in Ax2 cells was also observed (Supplementary Fig. S4D).

We observed increased spd and put levels in the samd ${ }^{O E}$ cells (Fig. 3A). Upon MGBG treatment, put and spd levels decreased in both $A \times 2$ and samdc ${ }^{O E}$ cells. Further, MGBG treatment decreased the levels of put and spd in both strains though the levels in sam$d c^{O E}$ cells remained higher than that observed in Ax2 cells. Nearly 2.7-folds increase in spd levels was observed in the overexpressing cells. Further, we observed an increase in put and spd but no change in spm levels during growth and development of samdc ${ }^{O E}$ as compared to Ax2 cells (Fig. 3B-D).

\section{Maintenance of polyamine homeostasis during development}

The mRNAlevels of the anabolic enzyme spd/spm synthase and the catabolic enzymes like spd/spm oxidase and SSAT showed a significant increase, decrease and insignificant change, respectively during development of the samdc ${ }^{O E}$ cells(Fig. 4A-C; Supplementary Fig. S5A-D, S6 A, B).

Next, we analysed the mRNA levels of few transporters (Supplementary Fig. S6C, D-S8) during development (Fig. 5) of the above strains. The mRNA levels of both DDB0185190 and DDB0233584

A

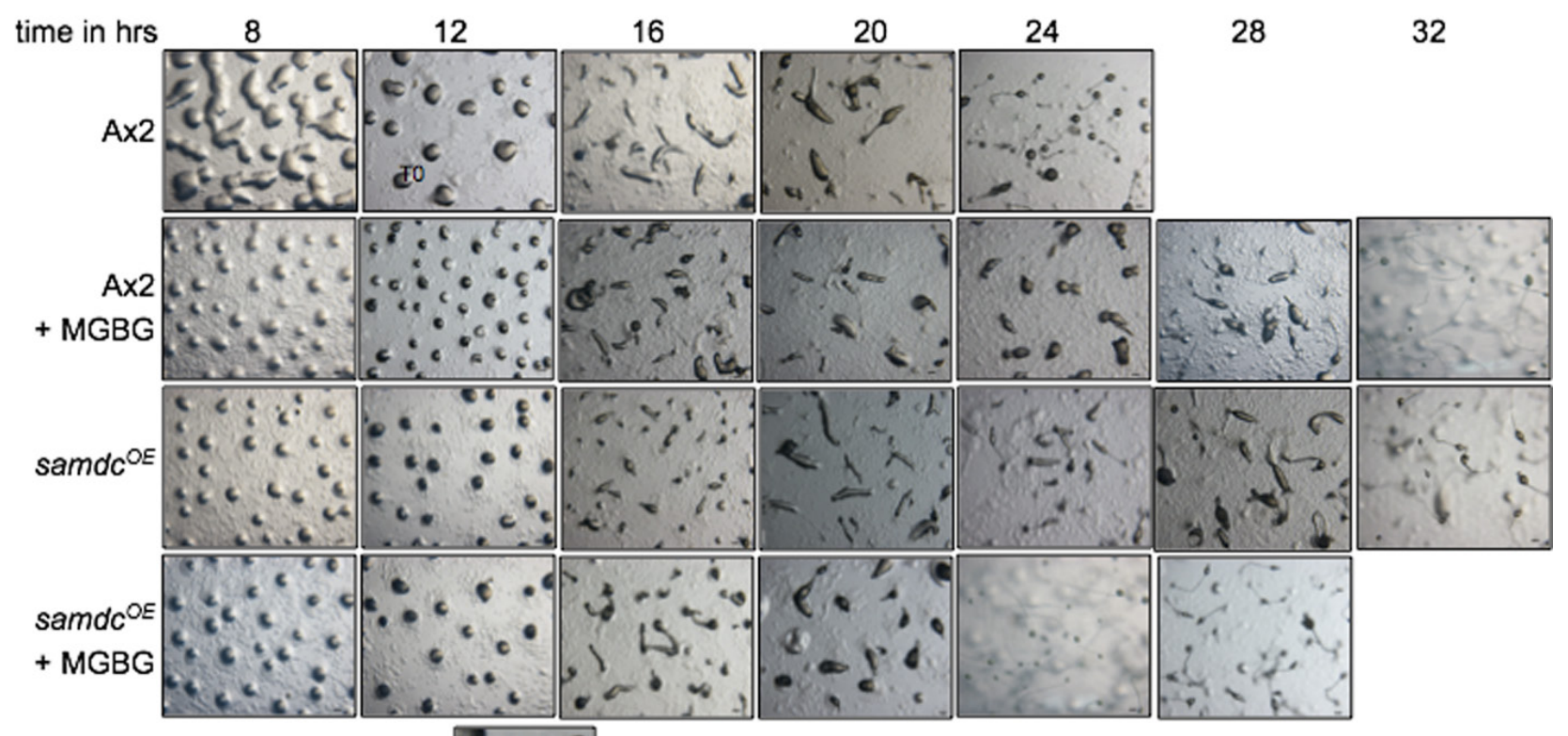

B

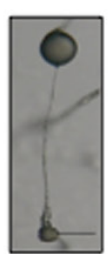

Ax2

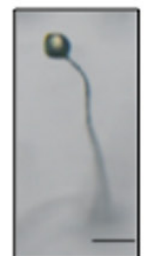

$\mathrm{A} \times 2+$ MGBG

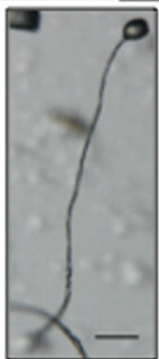

samdcoE MGBG

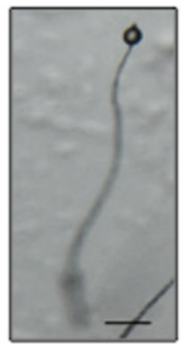

$\operatorname{samdc}^{\mathrm{OE}}+$
Fig. 2. Analyses of development of $A \times 2$ and samdc ${ }^{O E}$ cells in the presence and absence of methylglyoxal-bis (guanylhydrazone) (MGBG). (A) Time-specific developmental stages of Ax2, samdc ${ }^{\mathrm{OE}}$ in the presence and absence of MGBG $(1 \mathrm{mM})$. (B) The phenotype of the fruiting bodies observed under the same conditions. Number of structures analysed 200; $n=3$; scale: $100 \mu \mathrm{m}$. 

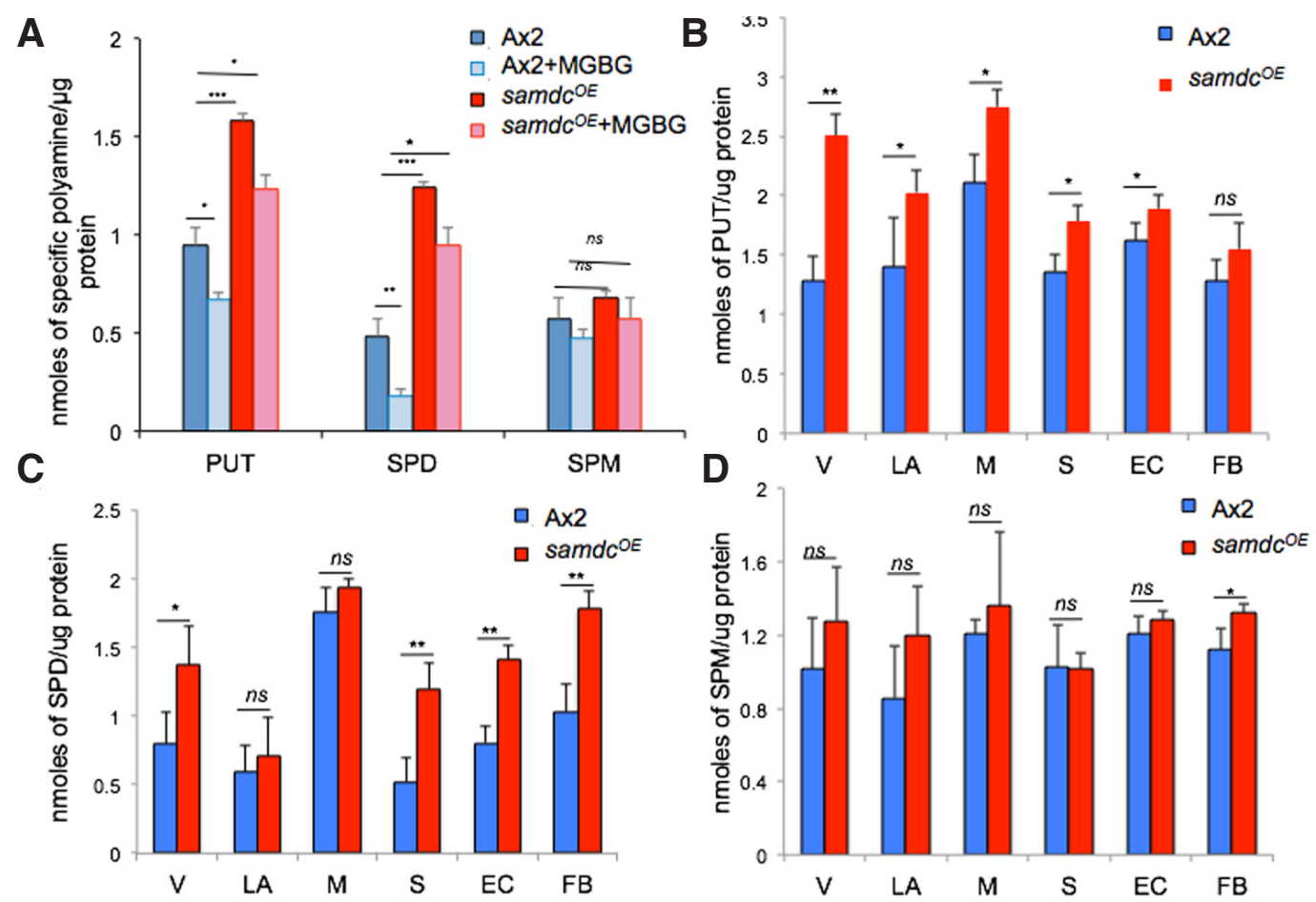

Fig. 3. Levels of polyamines in $A \times 2$ and samdc ${ }^{O E}$ cells in the presence or absence of methylglyoxal-bis (guanylhydrazone) (MGBG) during development. (A) Levels of polyamines in Ax2 and samdc ${ }^{\mathrm{OE}}$ cells. samdc ${ }^{\mathrm{OE}}$ cells showed increased polyamine levels while MGBG treatment decreased the levels. (B,C,D) Levels of put, spd and spm in the various developmental stages. The values representing mean \pm standard error (S.E.); $n=3 ;$ Student t-test, $p$-value $\leq 0.05, \leq 0.01$ and $\leq 0.001$ represented as ${ }^{*},{ }^{*}$ and ${ }^{* * *}$, respectively. Abbreviations: EC, early culminant; FB, fruiting body; LA, loose agreggate; $M$, mound; $S$, slug; $V$, vegetative.

A

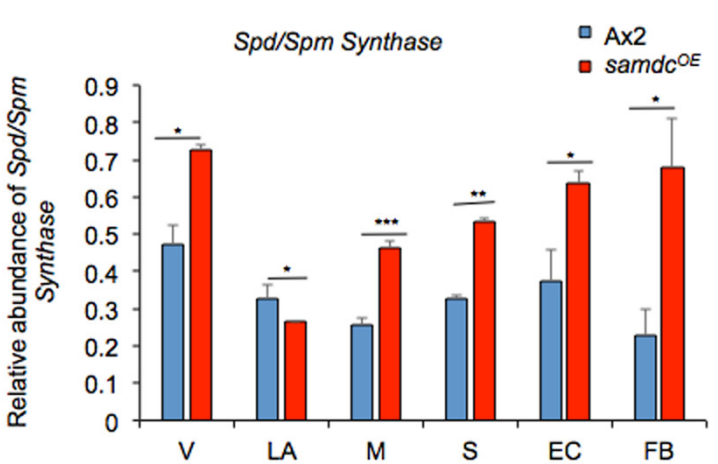

B

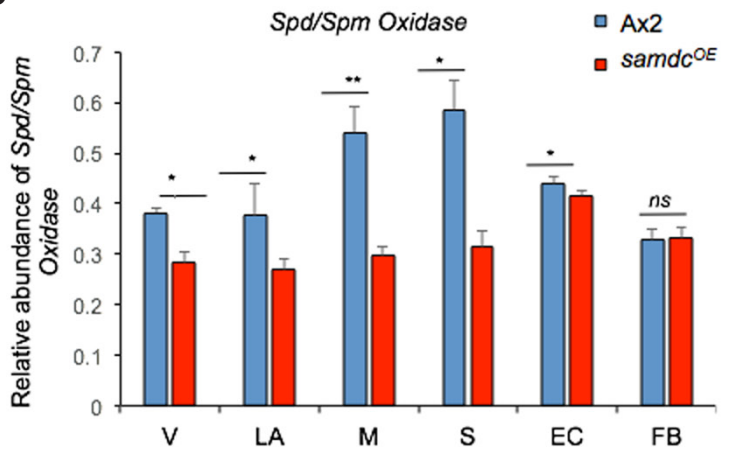

C

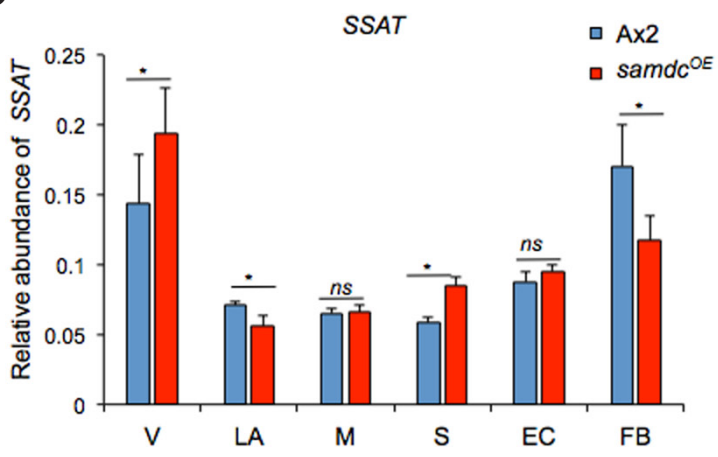

Fig. 4. samdc ${ }^{O E}$ cells show altered mRNA expression of biosynthetic genes involved in polyamine homeostasis. RT-PCR analyses of anabolic and catabolic genes, (A) Spd/Spm synthase; (B) Spd/spm Oxidase; (C) SSAT during development of Ax2 and samdc ${ }^{\mathrm{E}}$ cells after normalization to ig7 are shown. $n=3$; Student $t$-test, $p$-value $\leq 0.05, \leq 0.01$ and $\leq 0.001$ represented as * ${ }^{* *}$ and ***, respectively. Abbreviations, as in Fig. 3. 

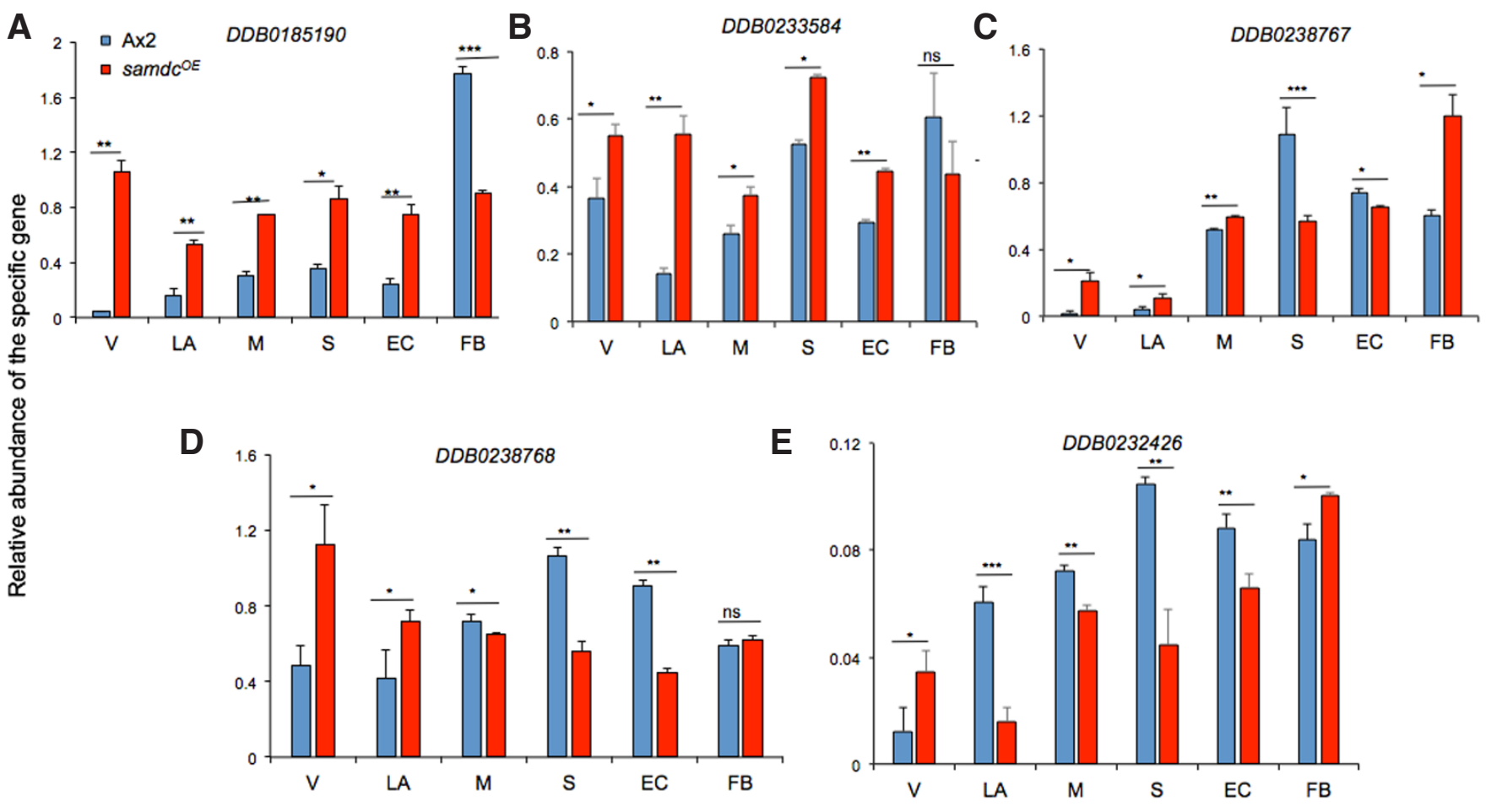

Fig. 5. samdc ${ }^{O E}$ cells show changes in mRNA expression of putative transporter genes involved in polyamine homeostasis. RT-PCR analyses of transporter genes: (A) DDB0185190, (B) DDB0233584, (C) DDB0238767, (D) DDB0238768, (E) DDB0232426 during development of Ax2 and samdc ${ }^{\text {OE }}$ cells after normalization to ig7 are shown. $n=3$; Student $t$-test, $p$-value $\leq 0.05, \leq 0.01$ and $\leq 0.001$ represented as ${ }^{*},{ }^{*}$ and ${ }^{* * *}$, respectively; Abbreviations, see Fig. 3.

during development showed an increase except in the fruiting body (Fig. 5 A,B). DDB0238767 did not show much change during development except for an abrupt two-folds increase in fruiting body (Fig. 5C). DDB023768 transcript was high till aggregation and decreased thereafter till it reached the Ax2 levels in fruiting body (Fig. 5D). DDB0232426 mRNA expression was decreased almost throughout development (Fig. 5E).

\section{Discussion}

Here, we succefully modulated the spd levels either by overexpressing the samdc gene or treating with its inhibitor MGBG. Our results showed spd levels could be brought down by MGBG but an effective amount of spd/PAs was required for growth to proceed. The samd ${ }^{O E}$ cells showed better cell proliferation with a possibility of increased put due to increased spd levels. Both MGBG treated $A \times 2$ and the samd $C^{O E}$ cells are of larger size suggesting it to be the possible reason for the slower cell proliferation. It suggests that both extremes: Iow (Ax2 + MGBG) and high ( $\left(\right.$ samd $^{\mathrm{O}}$ ) levels of spd were not beneficial for cell proliferation. Cell cycle data suggests a prestalk bias under different conditions, showing any alteration in spd levels lead towards the death/stalk pathway.

The put levels revert back to near normal with development but a significant increase in the spd levels was observed in samdc ${ }^{O E}$ cells. The initial increase in put may be involved in cell proliferation, as with development the levels declined and was comparable to wild-type in fruiting bodies suggesting conversion of put to spd or the efflux during development. The phenotype aberrations observed in samd ${ }^{O E}$ cells may not be due to put levels but to the increased spd levels observed during terminal differentiation. Also, the contribution of put during early development in influencing aggregation cannot be ruled out.

Reduction in PA levels lead to growth arrest (Imai et al., 2004), whereas surplus can cause cytotoxicity (Tobias and Kahana, 1995). The transcript levels of genes encoding proteins involved in PA biosynthesis (catabolic and anabolic) and the transporters (importers and exporters) were examined in both Ax2 and samdc ${ }^{O E}$ cells. Increased spd synthase transcript level especially during terminal differentiation, indicates the conversion of put into spd, which may be required to maintain high spd levels in samdc ${ }^{O E}$ cells. It is possible that this enzyme is required to overcome the efflux to maintain Spd/Spm intracellular levels. The mRNA levels of catabolic enzymes, spd/spm oxidase and SSAT were studied to analyse the feedback mechanism of PAlevel maintenance. Results with spd/spm oxidase suggests that during early development, the conversion to Spd/Spm does not take place as the levels of the intermediates may not be high but by the time of culmination when the actual levels of spd increased this enzyme reached wild-type levels. SSAT that is required to convert the intermediates to Spd/ Spm did not show much difference during development. This enzyme showed a significant decrease in fruiting body suggesting that it was not required for the maintenance of high spd levels observed in samdc ${ }^{O E}$ cells during terminal differentiation.

Increase in DDB0185190 mRNA levels during development (except in fruiting body) suggests it maybe an exporter helping maintain PA levels. Due to overexpression, spd levels remain high in samdc ${ }^{O E}$ cells. We observed normal levels of spm and put in fruiting body, it is possible that it helps in the efflux of PAs. Similar 
mRNA expression pattern was observed for DDB0233584 suggesting it to be involved in efflux. DDB0238767 did not show much change during development except in fruiting body and since the levels of put and spm was significantly high in fruiting body this may be active in efflux. DDB0232426 mRNA expression was decreased almost throughout development suggesting it to be a putative importer rather than an exporter. We could speculate it to be a spd importer, which is not required during the development of samdc ${ }^{O E}$ cells as they themselves maintain high spd levels.

In conclusion, a narrow range of spd levels must be maintained by the cell for proper growth and development. An increase/ decrease in the effective amount of PA is not good for the cell. A closer look at the biosynthetic and transporters genes of PA shows to be pretty conserved among different species. The results reveal a complex homeostatic mechanism at work for PA metabolism involving several parts of the pathway operating in a coordinated manner.

\section{Materials and Methods}

\section{Strains and development}

Cells were cutured in axenic medium $\mathrm{HL} 5$ at $22^{\circ} \mathrm{C}$ (with or without G418) under shaken conditions according to Maurya et al., (2017) and proliferation was monitored according to Mishra et al., (2017).

\section{Treatment with MGBG and spermidine}

Logarithmic phase cells were cultured in the absence and presence of $1 \mathrm{mM}$ (MGBG) (Sigma-Aldrich) or spd for $48 \mathrm{~h}$ at $22^{\circ} \mathrm{C}$ and developed.

\section{Cell-viability assay}

MTT (3- [4, 5-Dimethylthiazol-2-yl]-2,5-diphenyltetrazolium bromide) reduction assay was performed according to Swer et al., (2014) to monitor cell-viability.

\section{Cell cycle analysis by flow cytometry}

This was performed using FACS Calibur (Becton Dickinson, USA) according to Swer et al., (2014) both in the presence and absence of MGBG. Cell Quest software for acquisition and analysis was used.

\section{Measurement of various polyamine levels}

Polyamine was estimated as described previously (Saran, 1998; Kumar et al., 2014).

\section{Identification of genes involved in polyamine homeostasis}

To identify the genes involved in the polyamine homeostasis homologous genes of polyamine anabolism, catabolism and transporters were searched in the genomic database. The functional domains of these protein sequences were then run on BLASTp using Dictyostelium database to identify the proteins involved (Kumar, PhD thesis, JNU, 2012).

\section{RT-PCR}

Protocols for RNA isolation and RT-PCR (Reverse transcriptase-polymerase chain reaction) were followed as previously described (Maurya et al., 2017). Following cDNA synthesis, RT-PCR reactions were performed using gene-specific primer pairs (Supplementary Table S1) for various genes. $r n l A$ was used as an internal control (Gosain et al., 2012).

\section{Statistical analyses}

The statistical analyses were performed (mean standard deviation and standard error) and values were plotted in graph using Microsoft Excel-2013. Levels of significance were calculated using Student's t-test and p-values of less than 0.05 were considered as significant.

\section{Acknowledgements}

We gratefully acknowledge Mrs Tripti Panwar and Dr. Sarika Gupta from the CIF-SLS for their assistance in imaging and FACS, respectively.

\section{Funding}

Financial assistance from UGC, India [F. No. 42-181/2013(SR), 2013] and partial Institutional funding (DST-PURSE, UGC-Networking, FIST-II, UPE-II) to SS are acknowledged. PS thanks UGC for senior research fellowship.

\section{References}

GOSAIN A, LOHIA R, SHRIVASTAVA A, SARAN S (2012). Identification and characterization of peptide: N-glycanase from Dictyostelium discoideum. BMC Biochem. 8: 13-19.

HANDAAK, FATIMA T, MATTOO AK (2018) Polyamines: Bio-Molecules with Diverse Functions in Plant and Human Health and Disease. Front Chem. 6: 10.

IGARASHI K, KASHIWAGI K (1999). PA transport in bacteria and yeast. Biochem J 3: 633-642.

IMAI A, MATSUYAMA T, HANZAWA Y, AKIYAMA T, TAMAOKI M, SAJI H, SHIRANO $Y$, KATO T, HAYASHI H, SHIBATA D, TABATA S, KOMEDA Y, TAKAHASHI T (2004). Spd synthase genes are essential for survival of Arabidopsis. Plant Physiol 135: 1565-1573.

JAIN P, SHARMAP, SHRIVASTAVAA, SARAN S (2016). Dictyostelium discoideum: A Model System to Study Autophagy Mediated Life Extension. In Topics in biomedical Gerentology. (Eds. Pramod C Rath, Ramesh Sharma, S. Prasad). Springer, pp 35- 56. (ISBN: 978-981-10-2154-1).

KUMAR R (2012). Role of ornithine decarboxylase in the development and differentiation programme of Dictyostelium discoideum. Ph.D Thesis submitted to Jawaharlal Nehru University.

KUMAR R, RAFIA S, SARAN S (2014). Cloning, expression and characterization of the ornithine decarboxylase gene from Dictyostelium discoideum. Int $J$ Dev Biol 58: 669-676.

KUMAR R, SHARMA P, SARAN S (2018). Identification and cloning of S-adenosylmethionine decarboxylase (Samdc) gene from Dictyostelium discoideum. Int. J. Adv. Res. 6: 791-798.

MAURYAR, KUMARR, SARAN S (2017). Dictyostelium AMPKa regulates aggregatesize and cell-type patterning. Open Biol 7: 170055.

MISHRA H, SARAN S (2015). Classification and expression analyses of homeobox genes from Dictyostelium discoideum. J Biosci 40: 241-255.

MOSCHOU PN, SANMARTIN M, ANDRIOPOULOU AH, ROJO E, SANCHEZSERRANO JJ, AND ROUBELAKIS-ANGELAKIS KA (2008). Bridging the gap between plant and mammalian polyamine catabolism: a novel peroxisomal polyamine oxidase responsible for a full back-conversion pathway in Arabidopsis. Plant Physiol 147: 1845-1857.

REGENASS U, CARAVATTI, G, METT H, STANEK, J, SCHNEIDER P, MULLER M, MATTER A, VERTINO P, PORTER CW (1992). New S-adenosylmethionine decarboxylase inhibitors with potent anti tumor activity. Cancer Res 52:4712-4718.

SARAN S (1998). Changes in endogenous PA levels are associated with differentiation in Dictyostelium discoideum. Cell Biol Int 22: 575-580.

SWER PB, LOHIA R, SARAN S (2014). Analysis of rapamycin induced autophagy in Dictyostelium discoideum. Indian J Exp Biol 52: 295-304.

TARNITA CE, WASHBURNE A, MARTINEZ-GARCIA R, SGRO AE, LEVIN SA (2015). Fitness tradeoffs between spores and non-aggregating cells can explain the co-existence of diverse genotypes in cellular slime molds. Proc Natl Acad Sci USA 112: 2776-2781.

TOBIAS KE, KAHANA C (1995). Exposure to ornithine results in excessive accumulation of put and apoptotic cell death in ornithine decarboxylase overproducing mouse myeloma cells. Cell Growth Differ 10: 1279-1285.

WALLACE HM (1996). PAs in human health. Proc Nutr Soc 55: 419-431.

YE C, GENG Z, DOMINGUEZ D, CHEN S, FAN J, QIN L, LONG A, ZHANG Y, KUZEL TM, ZHANG B (2016). Targeting Ornithine decarboxylase by $\alpha$-Difluoromethylornithine inhibits tumor growth by impairing myeloid-derived suppressor cells. $J$ Immunol 196: 915-923. 


\section{Further Related Reading, published previously in the Int. J. Dev. Biol.}

Deletion of etoposide-induced 2.4 kb transcript (ei24) reduced cell proliferation and aggregate-size in Dictyostelium discoideum Neha Gupta and Shweta Saran

Int. J. Dev. Biol. (2018) 62: 273-283

https://doi.org/10.1387/ijdb.170327ss

YelA, a putative Dictyostelium translational regulator, acts as antagonist of DIF-1 signaling to control cell-type proportioning Yoko Yamada, Chris Sugden and Jeffrey G. Williams

Int. J. Dev. Biol. (2017) 61: 35-42

https://doi.org/10.1387/ijdb.160160yy

Dictyostelium discoideum Sir2D modulates cell-type specific gene expression and is involved in autophagy

Rakhee Lohia, Punita Jain, Mukul Jain, Pradeep Kumar Burma, Anju Shrivastava and Shweta Saran

Int. J. Dev. Biol. (2017) 61: 95-104

https://doi.org/10.1387/ijdb.160038ss

Cloning, expression and characterization of the ornithine decarboxylase gene from Dictyostelium discoideum

Rishikesh Kumar, Sheikh Rafia and Shweta Saran

Int. J. Dev. Biol. (2014) 58: 669-676

https://doi.org/10.1387/ijdb.140174ss

The Dictyostelium prestalk inducer DIF-1 directs phosphorylation of a bZIP transcription factor

Yoko Yamada, Yuzuru Kubohara, Haruhisa Kikuchi, Yoshiteru Oshima, Hong-Yu Wang, Susan Ross and Jeffrey G. Williams

Int. J. Dev. Biol. (2013) 57: 375-381

https://doi.org/10.1387/ijdb.130046jw

5 yr ISI Impact Factor $(2016)=2.421$

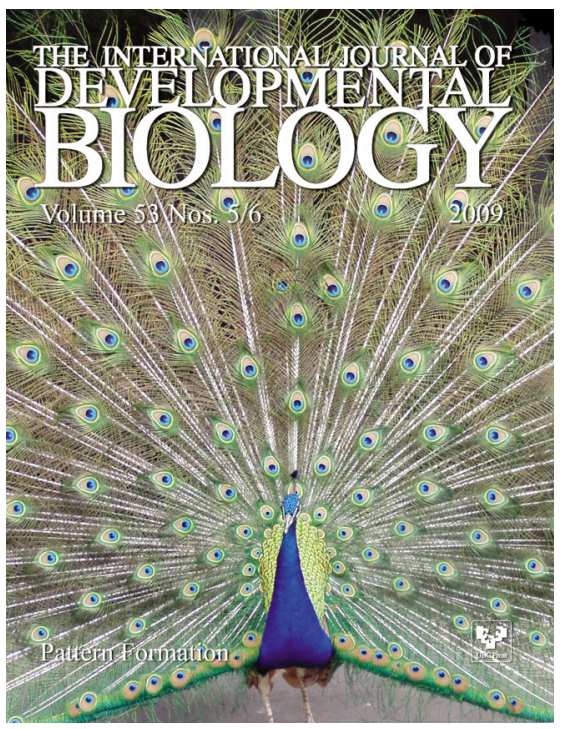

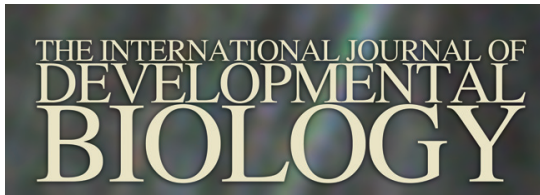

Volume 56 Nos $1 / 2 / 3$

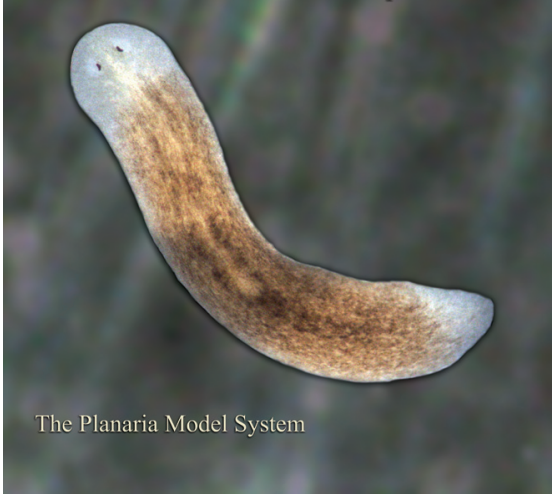

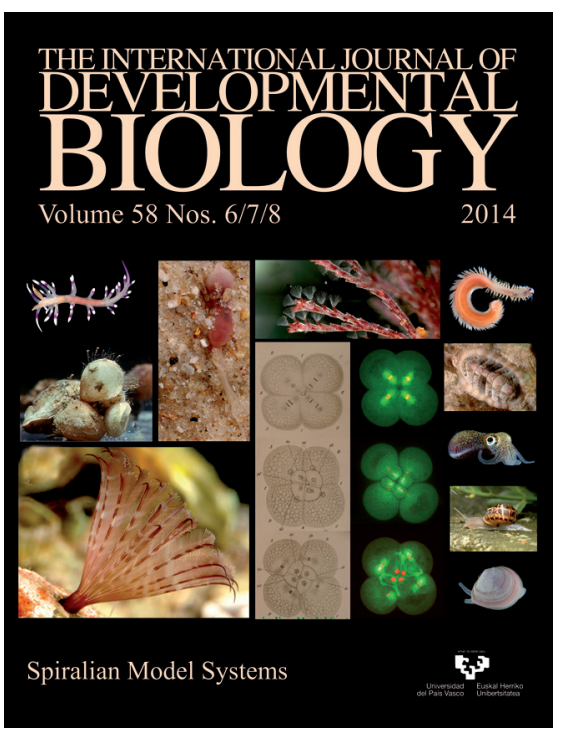

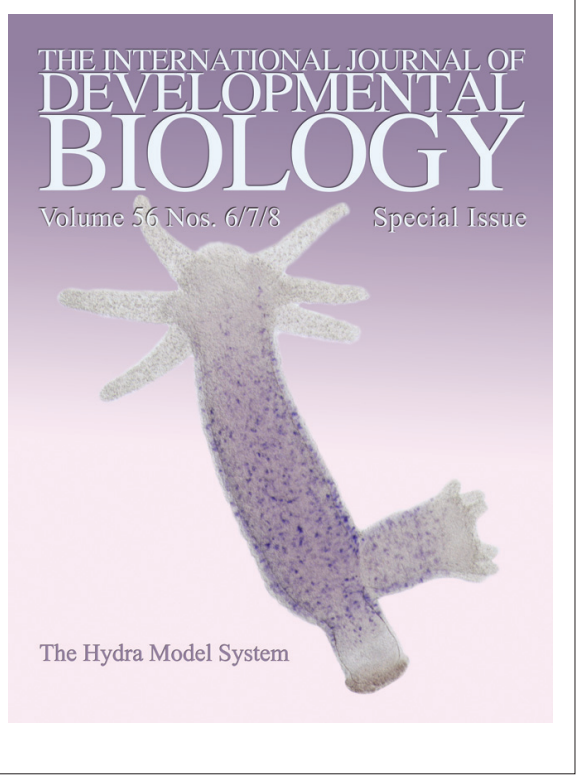

